\title{
New knowledge, new products and new processes
}

The scientific, economic and social scenarios present numerous opportunities for material innovation. This situation has some important determinants, with emphasis on the new concepts and tools that make up the nanoscience and the nanotechnologies, the wish to move to a sustainable global economy, the search for alternatives to oil as a source of energy, raw-materials and fertilizers and the migration of big populations to new consuming patterns, especially in Brazil, India and China.

Many actions involving the scientific research and both product and process development may respond simultaneously to several opportunities, having convergent results.

The transition to sustainability and the necessity of a gradual oil replacement lead to a great appreciation of the raw-materials from agriculture as well as of abundant minerals, the use of which does not imply high energy consumption or environmental costs. On the other hand, nanotechnologies, biotechnologies and the information technologies are allowing the upcoming of a lot of new functional materials that fulfill new functions in human life and their corresponding productive processes but according to energy and natural-resource saving patterns.

Brazil has an extremely favorable position in this scenario, with a high potential of energy raw-material production, such as alcohol, bio-diesel and solid biomass, which are also important chemical industry inputs, where they are transformed in monomers, plastifiers, surfactants, solvents, gums, fibers, plastics and rubbers, besides pharmaceuticals, aromas and many other kinds of products.

Nowadays, the production of "commodities" up to now considered as "petrochemical" can be more economically attractive, by means of the use of the sugar-cane ethanol. Besides that, many opportunities are brought by the use of natural latexes, vegetal oils, natural fibers, as well as an ample variety of agricultural residues together with many minerals, which, through different nanotechnologies, can be transformed into sophisticated materials, such as inorganic nanotubes, nanocomposites and several kinds of unprecedented hybrids. Some especially attractive cases are research objectives of the Inomat - National Institute of Science, Technology and Innovation in Functional Complex Materials, www.inomat.iqm.unicamp.br.
The Institute has just completed one year of existence and the report sent to $\mathrm{CNPq}$ - National Council of Technological and Scientific Development and FAPESP São Paulo Research Foundation - shows that all project quantitative goals have been met. Several qualitative results are highlighted in this report, representing relevant contributions to the advancement of the scientific frontier, achieved along the process of formation of highly-qualified human resources. The interaction between Inomat researchers and entrepreneurial development personnel is intense, in a constant dialogue that contributes to the definition of theme portfolios and research goals. Inomat members participate in prospection activities and science, technology and innovation observatories, such as the LQES News Bulletin, the Brazilian Agency for Industrial Development - ABDI's National Nanotechnology Strategies and the Center for Strategic Studies and Management in Science, Technology and Innovation CGEE's studies, thus contributing to overcome the wellknown limitations of the Science \& Technology area planning in Brazil.

So, Inomat is an answer to the present opportunities, putting into practice and deepening networked collaborativeresearch models and having as its mission the contribution to the knowledge frontier advance, associated with the transformation of knowledge in wealth-generating products and processes.

In the Inomat staff's practice, the scientific research results contribute to economic activities that, in turn, satisfy the society needs. On the other hand, the researcherbusiness people interaction enables the perception of demands and opportunities in several sectors of the economic activity, which is followed by new specific projects, the results of which reach the scientific literature and, at the same time, are shared with $\mathrm{R} \& \mathrm{D}$ professionals. This enhances the fast transformation of new science into incremental or radical development, innovating in products and processes.

\footnotetext{
Fernando Galembeck Inomat Chairman

Oswaldo L. Alves Inomat Vice-Chairman
} 